\title{
The Changes are Incorporated in Red Color Font Transcutaneous Ultrasonographic Assessment of Oral Submucous Fibrosis: A Preliminary Study
}

\author{
Poornima Rangaiah, ${ }^{1}$ Rajeshwari Gangappa Annigeri, ${ }^{2}$ and Ashok Lingappa ${ }^{1}$
}

Departments of ${ }^{1}$ Oral Medicine, and ${ }^{2}$ Radiology, Bapuji Dental College and Hospital, Davangere-577004 Karnataka, India.

\author{
Correspondence to : \\ Poornima Rangaiah \\ E-mail : drpoornima_omr@yahoo.co. \\ in
}

Keywords :

oral submucous fibrosis (OSMF), submucosal thickness, ultrasonography (USG).

\begin{abstract}
Oral submucous fibrosis (OSMF) is well recognized as one of the most common potentially premalignant conditions of the oral mucosa in India related to chewing of areca nut products and characterized by mucosal rigidity of varying intensity caused by fibroelastic changes of the juxta-epithelial layer, resulting in a progressive inability to open the mouth. The present study aimed to measure submucosal thickness by high frequency ultrasonography (USG) in cases and controls and to correlate this with clinical and histological severity of the disease. We conducted a hospital-based cross sectional study of 20 subjects who were clinically and histopathologically proven to have OSMF (cases) and 20 controls matched for age, sex and body mass index. Transcutaneous imaging of the buccal and labial submucosa was performed and the values were correlated with clinical stage and histological grade of the disease. Cases had increased submucosal thickness when compared to controls at all measured sites. The echogenicity pattern of cases showed areas of irregular hyperechoic linear streaks due to fibrotic submucosal deposits. In contrast, the submucosa of controls appeared as a hypoechoic band. To the best of our knowledge, this is the first study to use USG to measure the thickness of submucosal fibrosis in OSMF.
\end{abstract}

\section{Introduction}

In day-to-day clinical practice, dentists often encounter a wide spectrum of oral mucosal alterations. These may involve color, size, shape, or texture. They range from innocuous mucosal alterations needing simple therapeutic remedies to those requiring more interventional procedures. Many of these lesions are caused by chewing betel nut or smoking tobacco. Oral submucous fibrosis (OSMF) is an important example of these alterations.

OSMF is an insidious, chronic disease that can affect any part of the oral cavity and sometimes the pharynx (1). One of the most prevalent premalignant conditions in India, it is easy to diagnose but difficult to manage. At present it is considered an incurable and irreversible disease that is progressive in nature, even after cessation of the causative habit (2).

The etiopathogenesis of the disease remains elu- sive. Local factors have been implicated in the development of OSMF, the most common of which are chewing areca nut, pan masala, gutkha, arecanut and betel nut are synonyms for each other, panmasala is processed arecanut without betel leaf, Gutkha is a ready-made mixture of areca nut, tobacco, lime, catechu, sweetening agents, and flavoring compounds which is sold in small sachets or pouches_and chilies (3). Clinical and epidemiological observations have suggested that OSMF is increasingly associated with gutkha use rather than with chewing betel nut alone (3). Systemic factors such as nutritional deficiency, genetic factors, and autoimmunity have also been reported as contributing to the condition (4).

OSMF was once described as 'idiopathic scleroderma of the mouth' or 'sclerosing stomatitis' (5). It is similar to the autoimmune connective disease disorder systemic sclerosis in various respects, includ- 
ing clinical presentation, histological basis, and immunological findings (6). Ultrasonographic imaging has been conducted as an innovative and non-invasive tool for the evaluation of fibrosis of the oral mucosa in systemic sclerosis and for comparison with healthy individuals (7).

Ultrasonographic imaging is considered a form of "real-time" imaging. The echogenicity of a tissue is primarily related to its "stiffness", the chief source of which is collagen, or more specifically the content and arrangement of collagen within tissues. This is a major factor in the manner and extent to which the tissue attenuates the acoustic wave (8).

The technique is non invasive, produces no side effects, is capable of portraying soft tissue structure in considerable detail, and is readily accessible. Ultrasonography (USG) is particularly suitable for imaging superficial structures of the head and neck region (9).

USG provides both qualitative and quantitative assessment. Qualitatively, it provides information on the nature of a lesion, and its relation to adjacent normal structures. Quantitatively, it assesses the dimensions of the lesion, its distance from the skin surface, and its relative proximity to skin and mucosal surfaces (9).

\section{Materials and Methods}

The study recruited 40 subjects from the outpatient department of oral medicine and radiology. They were divided into 20 cases and 20 controls.

Criteria for cases were a habit of chewing gutkha or areca nut products and clinically and histologically proven OSMF. The control group was selected from those with no history of areca nut or gutkha chewing habit and no mucosal lesions of OSMF; controls were matched to cases by age, sex, and body mass index (BMI).

At the beginning of the study, information was given to all participants regarding the study's rationale and design and the need to undergo a clinical examination, blood tests, and USG and biopsy of the oral mucosa. Subjects who gave written informed consent on an institutionally approved form par- ticipated in the study.

The participants were comfortably seated on a conventional dental chair, and extraoral and intraoral examination was performed under artificial illumination. Participants also provided detailed personal history regarding their habit of chewing gutkha or areca nut. Clinical staging was performed according to the 1995 study of Khanna and Andrade (10) and histological grading was done according to criteria developed by Pindborg and Sirsat in 1966 (5).

Transcutaneous imaging was performed by a single trained general radiologist with the patient in the supine position. The USG device was an ENVISOR CHD (Philips medical systems, WA, USA) with a multifrequency linear transducer with a frequency ranging from 3-12 MHz. The transducer probe measured about $4 \mathrm{~cm}$ in length and $1 \mathrm{~cm}$ in width with a focal depth of approximately $6 \mathrm{~mm}^{-1} \mathrm{~cm}$. Before starting USG, participants were instructed to indicate the mucosa by placing the forefinger against the lining mucosa so as to delineate the empty space of the oral cavity, as stated by Wilson et al (9). The transducer probe was placed in such a way that the soft tissues were not unduly compressed, because excess contact pressure while imaging might affect the measurements. Hence, to obtain exact thickness measurements the probe was brought softly into contact with the surface (11).

For standardization of transcutaneous imaging of the buccal mucosa, an imaginary line was drawn between two points (Fig. 1). The first point was $1 \mathrm{~cm}$ anterior to the anterior border of the masseter muscle, indicating the posterior buccal mucosa (PBM), and the second was $1 \mathrm{~cm}$ posterior to the commissure of the lip (12), indicating the anterior buccal mucosa (ABM). The submucosal thickness was measured along this line on both right and left sides. Real-time imaging was performed with an extraoral approach by placing the transducer parallel to the lower border of the mandible (Fig. 2). For imaging upper labial mucosa (ULM) and lower labial mucosa (LLM) the transducer probe was placed in the mid region of upper and lower lip (philtrum and mentalis region), Since it is difficult to contour the 


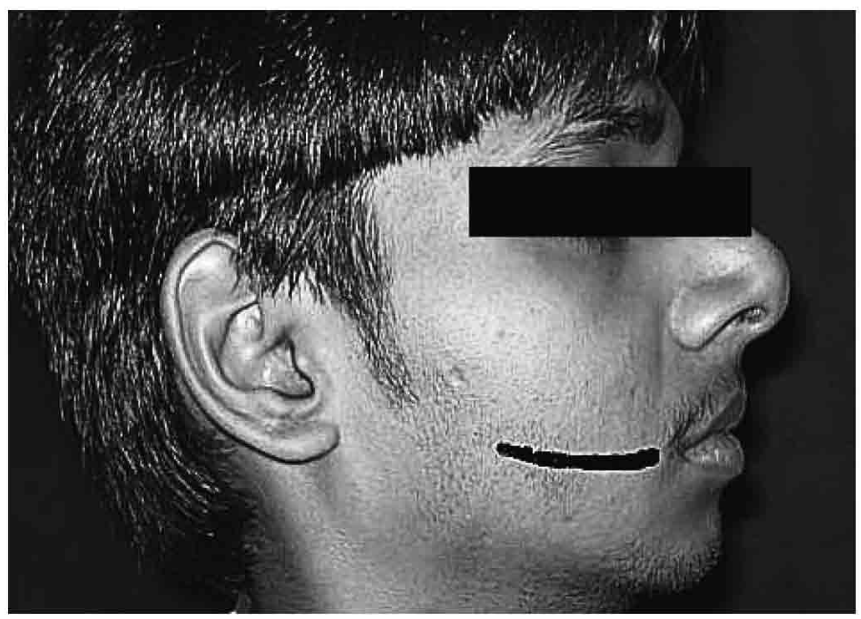

Fig. 1. USG measurements points on cheek.

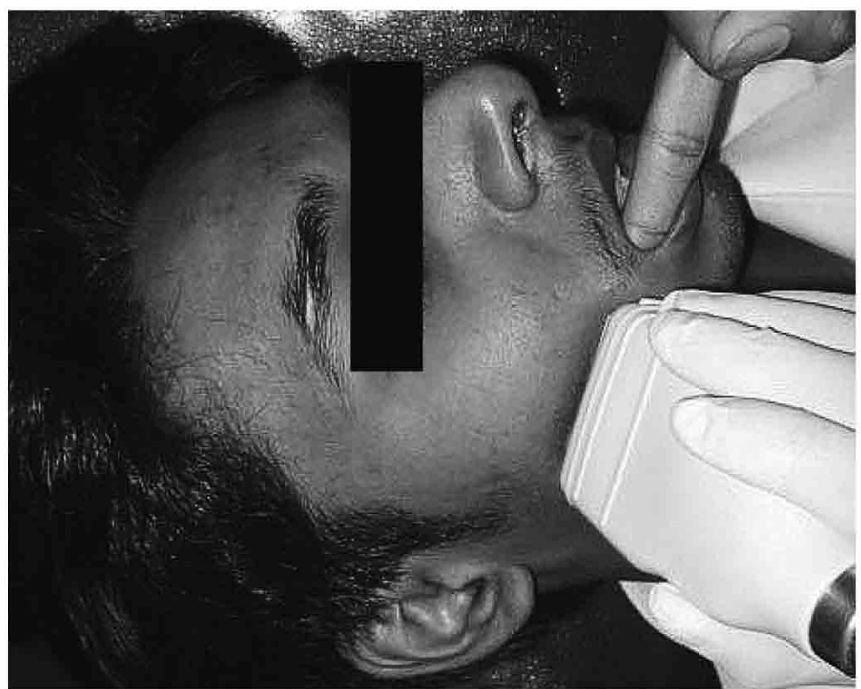

Fig. 2. Transducer placement for measurement of buccal mucosa.

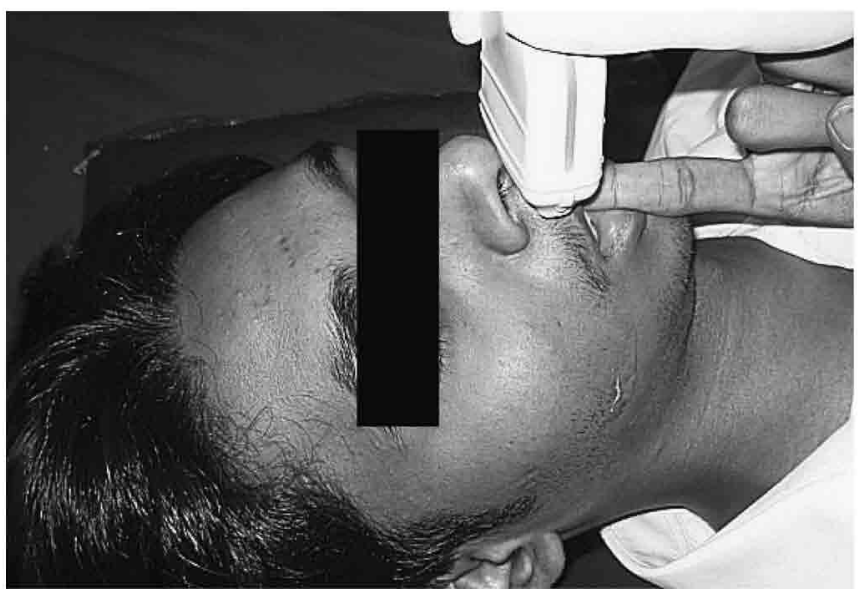

Fig. 3. Transducer placement for measurement of labial mucosa.

rigid transducer probe onto the flexible upper and lower lip respectively (Fig. 3).

The USG scan constituted a full representation of the cross section of the buccal and labial mucosa, in the submucosal and muscular planes. The mucosal lining was seen as a hyperechoic line, and the submucosa as a hypoechoic band supported by muscle planes. This band of hypoechogenicity between the hyperechoic mucosa and muscle layer was measured as the submucosa. The mean of right and left measurements was taken for the anterior and posterior buccal mucosa. Since differences in reliability of ultrasonic assessments of mucosal thickness in different parts of oral cavity may depend on the difficulties of repeatedly measuring at the same location,

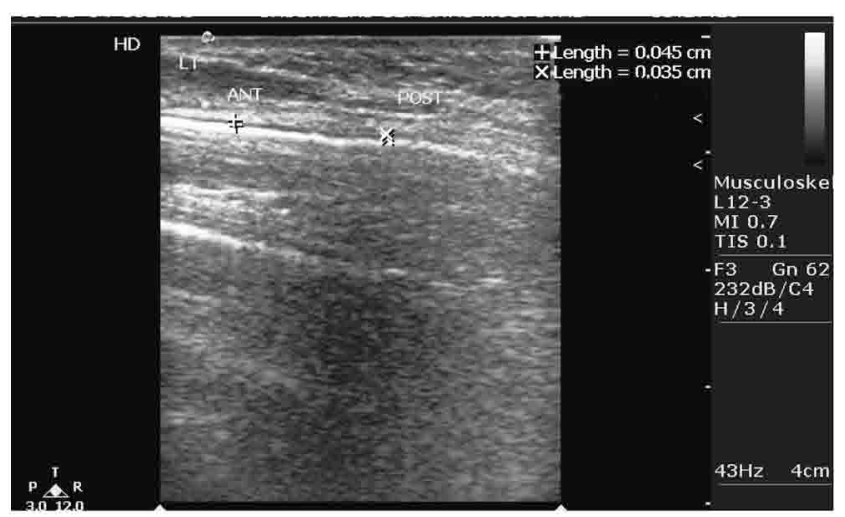

Control

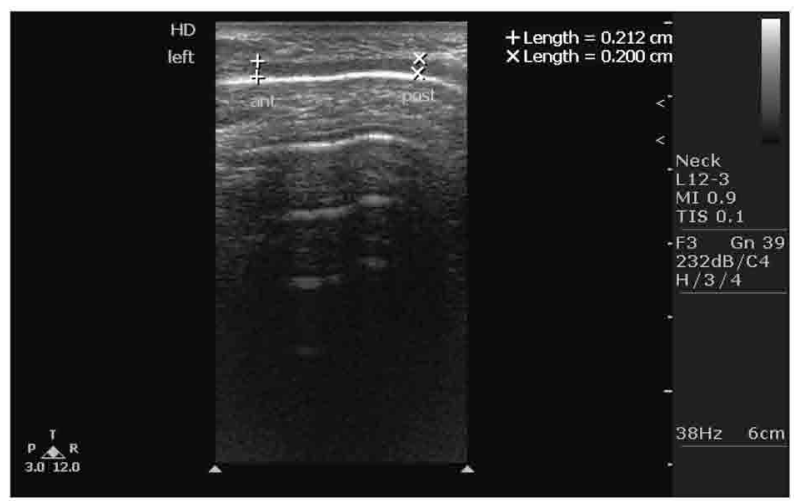

Case

Fig. 4. USG image of buccal mucosa in a Control \& Case. 


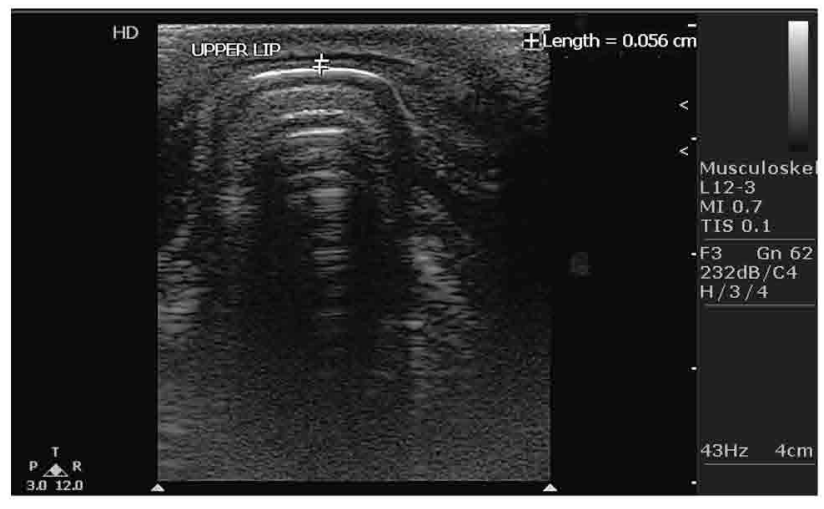

Control

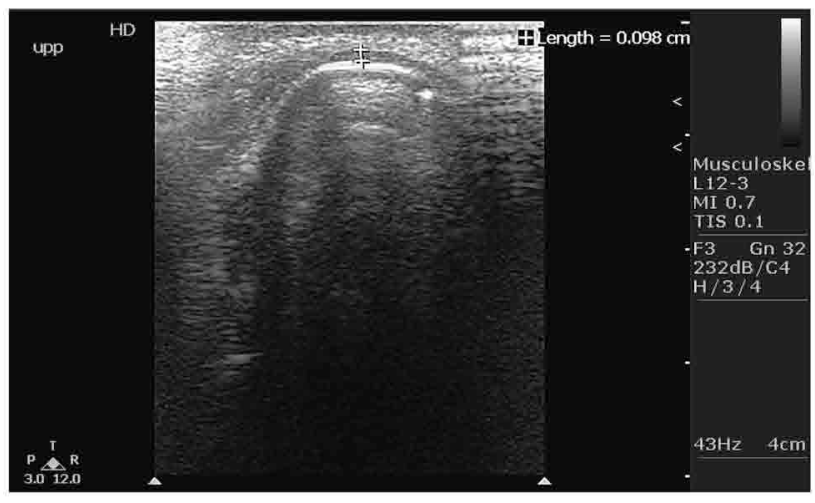

Case

Fig. 5. USG image of upper labial mucosa in a Control \& Case.

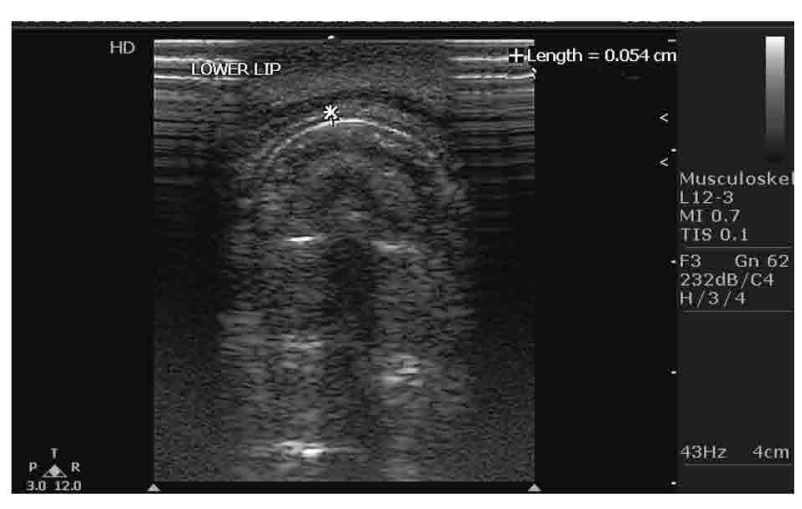

Control

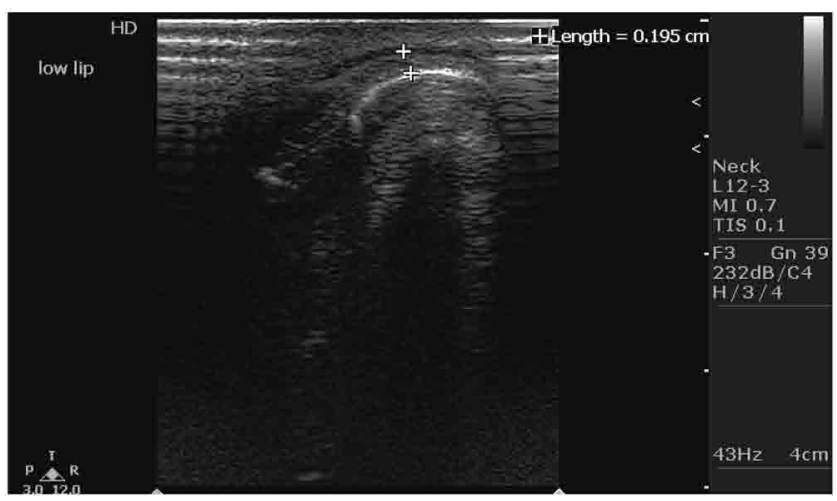

Case

Fig. 6. USG image of lower labial mucosa in a Control \& Case.

on varying thickness of tissue. These problems might be resolved by averaging multiple measurements (13). (since OSMF is a localized lesion and the disease severity varies at each site so it was necessary to take multiple measurements and averages. This information can be omitted by the reviewer) (Fig. 4 $-6)$.

\section{Statistical Analysis}

The results of this analytical case-control study are expressed as a Mean \pm SD and number and percentages. One way ANOVA was used for multiple group comparison and Student ' $t$ ' test for two group comparison. Non parametric Mann Whitney test was used when ever the data was skewed; Chi-square test was done for analyzing categorical data. For all the tests a $\mathrm{P}$ value of 0.05 or less was used for statistical significance.

\section{Results}

\section{Cases:}

All the 20 OSMF subjects were males in the age range of $20-36$ years with a mean age of $25.0 \pm 3.9$ years. The maximum number of subjects 11 (55\%) were in age group of $20-24$ years. 7 (35\%) were in age group of $25-29$ years and $2(20 \%)$ were in age group of $30-36$ years. The BMI of the study group ranged from $15.50-28.44$ with a mean of $21.5 \pm 3.6$.

All 20 cases had a gutkha chewing habit, of which 13 (65\%) chewed only gutkha, 4 (20\%) chewed gutkha with tobacco, and 3 (15\%) chewed gutkha and pan with tobacco. Duration of the habit was less than 3 years in 7 subjects (35\%), 4-7 years in $8(40 \%)$, and more than 8 years in $5(25 \%)$. The majority of subjects $(n=13,65 \%)$ had chewed these substances for 7 years or more and 7 (35\%) had done so for less than 7 years. Regarding frequency, 8 (40\%) subjects con- 
sumed $\leq 5$ packs/day, 6 (30\%) consumed 6-15 packs/ day, and 6 (30\%) consumed more than 16 packs/day. The majority of patients $(n=12,60 \%)$ consumed 15 packs/day or more and 8 (40\%) consumed fewer than 15 packs/day. All patients had retained the substance in the mouth : 5 (25\%) for less than 5 minutes, 5 (25\%) for 6-10 minutes, 3 (15\%) for $11-15$ minutes and 7 (35\%) for more than 15 minutes. Moreover, all 20 (100\%) subjects described a burning oral sensation and restricted mouth opening.

On general examination, subjects appeared healthy except for 4 (20\%) who showed pallor. Flattened (sunken) cheeks were noted in 16 (80\%). Bilateral masseter hypertrophy was present in 7 (35\%) subjects. On intra-oral examination, maximum interincisal mouth opening ranged from $10-45 \mathrm{~mm}$ with a mean of $22 \mathrm{~mm}$. Blanching and buccal fibrous bands were present in all 20 subjects (100\%) and labial bands in 17 (85\%). The floor of mouth was involved in $10(50 \%)$, the tongue in $3(15 \%)$, the uvula and faucial pillars in $16(80 \%)$, and the soft palate in 15 (75\%). The uvula was $\mathrm{J}$ shaped and shrunken in 9 (45\%) and bud shaped 2 (10\%). Restricted soft palate movement was seen in $14(70 \%)$ of cases and restricted tongue movement in 11 (55\%).

In terms of routine hematological investigations, hemoglobin concentration (grams/100 $\mathrm{ml}$ blood) was found equal to or less than 12 in 7 (35\%) and 12 or greater in $13(65 \%)$. Absolute eosinophilic count was normal, ranging from 100-250 cells/mm (3).

\section{Controls :}

Among the control group all subjects were male subjects with in the age range of $20-36$ years with a mean age of $25.1 \pm 4.0$ years. The BMI was in the range of $15.85-28.44$ with a mean of $21.6 \pm 3.7$.

Correlation between clinical stage and histological grade

Chi-square $\left(\chi^{2}\right)$ test was applied to assess the relationship between clinical stage and histological grade of OSMF. There was no significant association between these two variables $\left(\chi^{2}=12.7, \mathrm{P}=0.058\right.$, Table 1). Mann-Whitney test was also used here since these were non-parametric data, and this
Table 1. Correlation between clinical and histological staging

\begin{tabular}{|c|c|c|c|c|}
\hline \multirow{2}{*}{ Clinical stage } & \multicolumn{3}{|c|}{ Histological grade } & \multirow{2}{*}{ Total } \\
\cline { 2 - 4 } & I & II & III & \\
\hline I & 1 & - & - & 1 \\
\hline II & - & 4 & 1 & 5 \\
\hline III & 1 & 6 & 3 & 10 \\
\hline IV A & 1 & - & 3 & 4 \\
\hline Total & 3 & 10 & 7 & 20 \\
\hline
\end{tabular}

$\chi^{2}=12.7 \quad \mathrm{P}=0.058 \quad$ Not significant

showed that data were moderately skewed, suggesting an uneven distribution of sample size.

Correlation between frequency of chewing habit and clinical stage and histological grade

Chi-square $\left(\chi^{2}\right)$ test was applied to assess the relationship between frequency of chewing habit and clinical stage and between frequency of habit and histological grade. There was a significant correlation between frequency of habit and histological grade $\left(\chi^{2}=10.44, \mathrm{P}=0.034\right.$, Table 2$)$; as frequency of habit increased, histological grade increased significantly. Though there was no significance with respect to frequency of habit and clinical staging of the disease, but the numerical values in the table suggest that as the frequency increased the staging of the disease increased, this information can be deleted once the reviewer goes through.

Comparison of ultrasonographic submucosal thickness between cases and controls

As shown in Table 3, cases had significantly greater submucosal thickness of the ABM, PBM, ULM, and LLM when compared with the control group $(\mathrm{P}<0.01)$. Student ' $\mathrm{t}$ ' test was used for statistical correlation. In cases, the submucosa showed areas of irregular hyperechoic linear streaks caused by fibrotic deposits. In contrast, the submucosa of controls appeared as a hypoechoic band.

Relationship between submucosal thickness and frequency of chewing habit

On comparison of ABM measurement using ANOVA for frequency of habit between less than 5 packs/day and 6-15 packs/day and significant $\mathrm{P}$ 
Int J Oral-Med Sci 9(2):137-147, 2010

Table 2. Correlation of frequency of habit to clinical \& histological staging

\begin{tabular}{|c|c|l|c|c|c|c|c|c|}
\hline \multirow{2}{*}{$\begin{array}{c}\text { Frequency } \\
\text { (packs/day) }\end{array}$} & \multirow{2}{*}{$\begin{array}{c}\text { Number } \\
\text { of cases }\end{array}$} & \multicolumn{5}{|c|}{ Clinical stage } & \multicolumn{4}{|c|}{ Histological grade } \\
\cline { 3 - 10 } & & I & II & III & IV (A) & I & II & III \\
\hline$\leq 5$ & 8 & $1(12.5)$ & $1(12.5)$ & $3(37.5)$ & $3(37.5)$ & $1(12.5)$ & $2(25.0)$ & $5(62.5)$ \\
\hline $6-15$ & 6 & - & $4(66.7)$ & $2(33.3)$ & - & - & $6(100)$ & - \\
\hline$\geq 15$ & 6 & - & - & $5(83.3)$ & $1(16.7)$ & $2(33.3)$ & $2(33.3)$ & $2(33.4)$ \\
\hline Total & 20 & 1 & 5 & 10 & 4 & 3 & 10 & 7 \\
\hline \multicolumn{7}{c}{$\chi^{2}=12.04 \quad \mathrm{P}=0.06$} & Not significant $\chi^{2}=10.44 \quad \mathrm{P}=0.034 \quad$ Significant
\end{tabular}

$\mathrm{P}$ Value of $<0.05$ is considered significant

Table 3. Comparison of ultrsonographic measurements (cms) of submucosal thickness in study \& control group

\begin{tabular}{|c|c|c|c|c|c|}
\hline \multicolumn{2}{|c|}{} & ABM & PBM & ULM & LLM \\
\hline $\begin{array}{c}\text { Cases } \\
(\mathrm{n}=20)\end{array}$ & $\begin{array}{c}\text { Mean } \\
\text { thickness } \pm \mathrm{SD} \\
(\mathrm{cm})\end{array}$ & $0.209 \pm 0.072$ & $0.218 \pm 0.080$ & $0.149 \pm 0.051$ & $0.162 \pm 0.052$ \\
\hline \multicolumn{2}{|c|}{ Range $(\mathrm{cm})$} & $0.079-0.313$ & $0.096-0.342$ & $0.079-0.248$ & $0.062-0.252$ \\
\hline $\begin{array}{c}\text { Controls } \\
(\mathrm{n}=20)\end{array}$ & $\begin{array}{c}\text { Mean } \\
\text { thickness } \pm \mathrm{SD} \\
(\mathrm{cm})\end{array}$ & $0.056 \pm 0.011$ & $0.057 \pm 0.010$ & $0.055 \pm 0.015$ & $0.060 \pm 0.017$ \\
\hline \multicolumn{2}{|c|}{ Range $(\mathrm{cm})$} & $0.036-0.071$ & $0.036-0.076$ & $0.035-0.103$ & $0.026-0.104$ \\
\hline \multicolumn{2}{|c|}{ Mean difference $(\mathrm{cm})$} & 0.153 & 0.161 & 0.094 & 0.102 \\
\hline \multicolumn{2}{|c|}{$\mathrm{t}$} & 9.34 & 9.37 & 7.89 & 7.95 \\
\hline \multicolumn{2}{|c|}{$\mathrm{P}$} & $<0.001 \mathrm{HS}$ & $<0.001 \mathrm{HS}$ & $<0.001 \mathrm{HS}$ & $<0.001 \mathrm{HS}$ \\
\hline
\end{tabular}

HS, highly significant.

ABM- Anterior buccal mucosa

PBM- Posterior buccal mucosa

ULM- Upper labial mucosa

LLM- Lower labial mucosa

value was obtained, and also when comparison of ABM of subjects with frequency of chewing 6-15 to more than 15 packs/day a significant $\mathrm{P}$ value of $<0.01$ was obtained. When PBM thickness was assessed with respect to frequency of chewing habit, an ' $F$ ' value of 2.08 was obtained, which was not significant (Table 4). However, there was a non-significant tendency for PBM thickness to increase in those who used fewer than 5 packs/day compared with those who used more than 15 packs/day.

When ULM and LLM thicknesses were assessed with respect to frequency of habit, ' $F$ ' values of 4.69 (for ULM) and 4.66 (for LLM) were obtained. There was a significant increase in ULM and LLM thickness for subjects who used 6-15 packs/day when compared with those who used more than 15 packs/ day $(\mathrm{P}<0.05)$.

Relationship between submucosal thickness and duration of chewing habit

For these statistical correlations ANOVA was used, which gave an ' $\mathrm{F}$ ' value of 0.45 for ABM, 1.25 for PBM, 1.33 for ULM and 0.92 for LLM (Table 5). These correlations were not significant. For ABM, PBM, ULM, and LLM, there was a non-significant tendency toward an increase in submucosal thickness for subjects who had chewed substances for more 
Int J Oral-Med Sci 9(2):137-147, 2010

Table 4. Comparison of ultrasonographic measurements with frequency of the habit

\begin{tabular}{|c|c|c|c|c|c|}
\hline $\begin{array}{l}\text { Frequency } \\
\text { (packs/day) }\end{array}$ & No. of cases & $\mathrm{ABM}$ & PBM & ULM & LLM \\
\hline$\leq 5$ & $8(40 \%)$ & $0.245 \pm 0.060$ & $0.228 \pm 0.092$ & $0.155 \pm 0.059$ & $0.187 \pm 0.064$ \\
\hline 6-15 & $6(30 \%)$ & $0.135 \pm 0.057$ & $0.170 \pm 0.053$ & $0.107 \pm 0.018$ & $0.109 \pm 0.046$ \\
\hline$\geq 15$ & $6(30 \%)$ & $0.234 \pm 0.047$ & $0.252 \pm 0.054$ & $0.182 \pm 0.035$ & $0.182 \pm 0.028$ \\
\hline \multicolumn{2}{|c|}{ ANOVA } & $\begin{array}{c}7.53 \\
<0.01 \\
\text { Significant }\end{array}$ & $\begin{array}{c}2.08 \\
0.16 \mathrm{NS}\end{array}$ & $\begin{array}{c}4.69 \\
<0.05 \\
\text { Significant }\end{array}$ & $\begin{array}{c}4.66 \\
<0.05 \\
\text { Significant }\end{array}$ \\
\hline
\end{tabular}

NS, not significant

ABM- Anterior buccal mucosa

PBM- Posterior buccal mucosa

ULM- Upper labial mucosa

LLM- Lower labial mucosa

Table 5. Comparison of ultrasonographic measurements $(\mathrm{cms})$ with duration of the habit (in years)

\begin{tabular}{|c|c|c|c|c|c|c|}
\hline $\begin{array}{c}\text { Duration } \\
\text { (years) }\end{array}$ & & & $\mathrm{ABM}$ & PBM & ULM & LLM \\
\hline$<3$ & & & $0.188 \pm 0.083$ & $0.185 \pm 0.090$ & $0.125 \pm 0.044$ & $0.139 \pm 0.068$ \\
\hline $4-7$ & & & $0.214 \pm 0.075$ & $0.228 \pm 0.069$ & $0.155 \pm 0.055$ & $0.181 \pm 0.060$ \\
\hline$\geq 8$ & & & $0.228 \pm 0.055$ & $0.247 \pm 0.063$ & $0.171 \pm 0.049$ & $0.164 \pm 0.044$ \\
\hline \multicolumn{2}{|c|}{ ANOVA } & $\begin{array}{l}F \\
P\end{array}$ & $\begin{array}{c}0.45 \\
0.65 \mathrm{NS}\end{array}$ & $\begin{array}{c}1.25 \\
0.35 \mathrm{NS}\end{array}$ & $\begin{array}{c}1.33 \\
0.29 \mathrm{NS}\end{array}$ & $\begin{array}{c}0.92 \\
0.42 \mathrm{NS}\end{array}$ \\
\hline
\end{tabular}

ABM- Anterior buccal mucosa

PBM- Posterior buccal mucosa

ULM- Upper labial mucosa

LLM- Lower labial mucosa

than 8 years compared with those who had done so for less than 3 years.

Relationship between submucosal thickness and duration of oral retention

For statistical correlation ANOVA was used which gave a ' $F$ ' value of 1.17, 1.54, 3.27, 2.28 for ABM, PBM, ULM, LLM respectively. ANOVA showed that duration of oral retention had a significant effect on ULM thickness (Table 6). Subjects who retained the substance for $6-10$ minutes had significantly greater ULM thickness than those who did so for 11-15 minutes.

Relationship between submucosal thickness and clinical stage

At all the measured sites, $\mathrm{F}$ values obtained by
ANOVA were less than 1 and $\mathrm{P}$ values exceeded 0.05 , indicating no significant relationship between submucosal thickness and clinical stage (Table 7). The differences in $\mathrm{P}-$ values and in mucosal thickness between clinical stage III and IVA could be attributed to greater numbers of subjects; i.e., 10 (50\%) for clinical stage III compared with $4(20 \%)$ subjects for clinical stage IVA.

\section{Discussion}

OSMF is one significant example of a health condition related to gutkha chewing. It is one of the most prevalent premalignant conditions among Indians and people of Indian origin living outside India; it also occurs occasionally in other Asians, and sporad- 
Int J Oral-Med Sci 9(2):137-147, 2010

Table 6. Comparison of ultrasonographic measurements (cms) with duration of quid keeping habit (in minutes)

\begin{tabular}{|c|c|c|c|c|c|}
\hline $\begin{array}{l}\text { Oral retention } \\
\text { (minutes) }\end{array}$ & No. of cases & $\mathrm{ABM}$ & PBM & ULM & LLM \\
\hline$\leq 5$ & $5(25 \%)$ & $0.179 \pm 0.076$ & $0.213 \pm 0.052$ & $0.137 \pm 0.048$ & $0.148 \pm 0.060$ \\
\hline $6-10$ & $5(25 \%)$ & $0.184 \pm 0.087$ & $0.170 \pm 0.096$ & $0.130 \pm 0.044$ & $0.136 \pm 0.055$ \\
\hline $11-15$ & $3(15 \%)$ & $0.263 \pm 0.050$ & $0.282 \pm 0.084$ & $0.221 \pm 0.023$ & $0.234 \pm 0.019$ \\
\hline$\geq 15$ & $7(35 \%)$ & $0.224 \pm 0.047$ & $0.228 \pm 0.062$ & $0.139 \pm 0.046$ & $0.160 \pm 0.057$ \\
\hline \multicolumn{2}{|c|}{ ANOVA } & $\begin{array}{l}1.17 \\
0.25\end{array}$ & $\begin{array}{l}1.54 \\
0.24\end{array}$ & $\begin{array}{c}3.27 \\
<0.05 \\
\text { Significant }\end{array}$ & $\begin{array}{l}2.28 \\
0.118\end{array}$ \\
\hline
\end{tabular}

ABM- Anterior buccal mucosa

PBM- Posterior buccal mucosa

ULM- Upper labial mucosa

LLM- Lower labial mucosa

Table 7. Comparison of ultrasonographic measurements with clinical staging

\begin{tabular}{|c|c|c|c|c|c|}
\hline Clinical stage & No. of cases & $\mathrm{ABM}$ & PBM & ULM & LLM \\
\hline I & $1(5 \%)$ & 0.193 & 0.204 & 0.132 & 0.186 \\
\hline II & $5(25 \%)$ & $0.177 \pm 0.094$ & 0.203 & $0.139 \pm 0.064$ & $0.147 \pm 0.066$ \\
\hline III & $10(50 \%)$ & $0.225 \pm 0.069$ & 0.234 & $0.157 \pm 0.046$ & $0.165 \pm 0.056$ \\
\hline IV A & $4(20 \%)$ & $0.214 \pm 0.064$ & 0.206 & $0.146 \pm 0.064$ & $0.168 \pm 0.080$ \\
\hline \multicolumn{2}{|c|}{ ANOVA } & $\begin{array}{l}0.47 \\
0.71\end{array}$ & $\begin{array}{l}0.19 \\
0.90\end{array}$ & $\begin{array}{l}0.18 \\
0.91\end{array}$ & $\begin{array}{l}0.16 \\
0.92\end{array}$ \\
\hline
\end{tabular}

ABM- Anterior buccal mucosa

PBM- Posterior buccal mucosa

ULM- Upper labial mucosa

LLM- Lower labial mucosa

ically in Europeans. In India, OSMF has prevalence ranging from $0.2 \%$ to $1.2 \%$ (14) and a malignant transformation rate of $3-7.6 \%(15-17)$. The most widely accepted etiologic agent is areca nut-in raw form, betel quid, pan masala, or gutkha. Other predisposing factors such as consumption of chilies, consumption of hot and spicy foods not chewing of chillies, this information can be omitted in print nutritional deficiency, immunologic factors, and genetic susceptibility have also been implicated in $\operatorname{OSMF}(4,18,19)$.

The age characteristics of the present study group were in accordance with the reported mean age of OSMF patients of 26.1 years (15). The majority of the present cases $(90 \%, n=18)$ were in the age range of 21 -30 years, This is in agreement with the reported age of OSMF patients in several studies $(3,20,21)$. The higher incidence of OSMF in younger people is attributed to the prevalence of gutkha chewing in this age group, which in turn relates to the substance's easy accessibility and low cost.

All 20 subjects were men, suggesting an extreme male predominance similar to that reported in several previous studies $(22,23)$. The male predominance in the present study may relate to the fact that gutkha is more available to men than women in Indian society. It may also reflect the changing lifestyle of young Indian men. In the present study 
burning sensation and restricted mouth opening was present in all cases. We are correlating our findings with the studies which are available, hence indicated by references $(24,25)$.

In the present study, all 20 OSMF patients had the habit of gutkha chewing. Epidemiological studies, case reports, case control studies, animal experiments, and tissue culture studies have all suggested that chewing of areca nut products is the main etiologic factor in OSMF. Gutkha is a ready-made mixture of areca nut, tobacco, lime, catechu, sweetening agents, and flavoring compounds which is sold in small sachets or pouches (20). In the present study, we found buccal fibrous bands in $100 \%(n=20)$ of cases, $(10,26)$, labial bands in $85 \%$ we are discussing our results and also correlating them to available literature since our study is aimed to measure buccal and labial submucosa sonographically.

The majority of our patients had a hemoglobin percentage $(\mathrm{Hb} \%)$ of more than $12 \mathrm{gms} \%$ which is consistent with a hematological study of OSMF where no statistical difference in hemoglobin level was found between patients and controls (27). In the present study we did not find eosinophilia, which conflicts with several previous studies that have found increased eosinophil counts in $\operatorname{OSMF}(27,28)$.

We found no significant correlation between clinical stage and histological grade of OSMF. Because of inaccessibility due to restricted mouth opening, biopsies from OSMF patients were not always taken from the fibrous bands, which tended to be in the posterior part of the oral cavity. This might explain the lack of correlation between clinical stage and histological grade of the disease. The present findings are in agreement those of previous studies of OSMF that found no correlation between clinical and histopathological features (29), or between mouth opening and involvement of muscle fibers (30). it is important since our study also did not find any correlation between the disease clinically and histologically.

We found a significant correlation between frequency of chewing habit and both clinical stage and histological grade. As frequency of chewing habit increased, disease severity also increased. This is in accordance with previous studies $(29,30)$.

Interestingly, however, we found no correlation between duration of chewing habit and either clinical stage or histological grade $(29,31)$. Hence, our correlation is compatible with studies where they have told daily consumption was more significant than the total duration of habit, and daily consumption rate appears to be much more significant with respect to risk than the lifelong duration of the habit (32). We found a highly significant difference in submucosal thickness between cases and controls. There is a scarcity of reported measurements of submucosal thickness on OSMF, meaning that we cannot compare the present results with those of other studies. However, some have measured the masticatory mucosa $(33,34)$, gingival thickness $(13,35)$, or alveolar mucosal thickness (11). The studies quoted above are few examples of studies available wherein sonography was used as a diagnostic method to measure the mucosal thickness but not in OSMF.

A significant positive correlation was obtained in relation to ABM, ULM, and LLM thickness and frequency of chewing habit. This concords with the findings of previous studies showing that the frequency of the chewing habit was correlated with the severity of OSMF $(29,31)$. Frequency of the chewing habit can be indirectly related to the pathogenesis of the disease wherein the normal oral mucosa is exposed to more and more areca nut, which acts as a chronic irritant causing mechanical trauma. Slaked lime, which is one of the ingredients of gutkha causes chemical burns leading to microhemorrhage. Both mechanical and chemical irritation are followed by infiltration of fibroblasts, hence an increase in fibrosis (36). In the present study, submucosal thickness was decreased in $30 \%(\mathrm{n}=6)$ patients who chewed 6-15 packs/day compared to $40 \% \quad(n=8)$ subjects who chewed $\leq 5$ packs/day. This may be explained by the disparity in number of subjects in each group. As the frequency increased to more than $15 \mathrm{packs} / \mathrm{day}$, we observed a definite increase in submucosal thickness in all areas when compared with subjects who used 6-15 packs/day. 
We observed no statistically significant association between duration of substance retention in the mouth and submucosal thickness at any site. This may be explained by the fact that though areca nut acts as the main predisposing factor to OSMF, autoimmunity, and genetic predisposition also play important roles in the occurrence as well as progression of the disease $(37,38)$. This is also supported by a few studies reporting OSMF in individuals who have not chewed areca nut products $(18,39)$.

The current study showed an increase in submucosal thickness from clinical stage II to stage III in the ABM, PBM, ULM, and LLM, as well as a slight increase in submucosal thickness between clinical stage III and IVA in the LLM. In comparison, with an increase in submucosal thickness was present from histological grade II to grade III in ABM and PBM, and there was a slight increase in submucosal thickness from grade I to grade III. Although these findings were not statistically significant, they suggest a possible correlation between submucosal thickness and clinical stage. Our study might have failed to elucidate a statistically significant correlation because of the relatively small sample size and possible heterogeneous distribution of number of cases among different clinical stages (the relatively few cases with clinical stage I and IVA disease may have resulted in bias). This clearly indicates the necessity of increasing the sample size and having adequate numbers of patients for each clinical stage. Since this study is, to our knowledge, the first of its kind to assess the relationship between the two selected primary variables, it provides an insight for required modifications in future studies and to that extent it is heuristic.

\section{Conclusion}

USG is a noninvasive technique accepted readily by patients, and a comparatively cheap diagnostic modality. Uncertainties remain regarding the association with OSMF of frequency of chewing habit, duration of this habit, and retention of areca nut products in the mouth. The present study looked only at the submucosal region, which is replaced by fi- brosis in this disease. However, OSMF also involves the underlying muscles, which may be one of the reasons for restricted mouth opening. Application of intraoral transducers might yield more accurate and reliable measurements of the submucosa. Hence, future studies are recommended to address these factors and hopefully reach clearer conclusions. We conclude that the present preliminary study was able to establish the normal ultrasonographic values of submucosal thickness for a small sample of the South Indian population. This study showed a significant increase in USG-measured submucosal thickness in OSMF patients.

\section{References}

1. Rajendran R: Oral submucous fibrosis: etiology, pathogenesis, and future research. Bulletin of WHO, 72: 985-996, 1994.

2. Gupta SC, Yadav YC: "MISI" an etiologic factor in oral submucous fibrosis. Indian Jr of Otolaryngology, $30: 5-6,1978$.

3. Haider SM, Merchant AT, Fikree FF, Rahbar MH : Clinical and functional staging of oral submucous fibrosis. Br J Oral Maxillofacial Surg, 38 : 12-15, 2000.

4. Cox SC, Walker DM: Oral submucous fibrosis, a review. Australian Dental Journal, 41 : 294-299, 1996.

5. Pindborg JJ, Sirsat SM: Oral submucous fibrosis. Oral Surg Oral Med Oral Pathol, 22 : 764-779, 1966.

6. Wood RE, Lee P : Analysis of the Oral manifestations of Systemic Sclerosis. Oral Surg Oral Med Oral Pathol, 65 : 172-175, 1988.

7. Jackowski J, Johren P, Muller AM, Kruse A, Dirschka $\mathrm{T}$ : Imaging of fibrosis of the oral mucosa by $20 \mathrm{MHz}$ sonography. Dentomaxillofac Radiol, 28: 290-294, 1999.

8. Price RR, Jones TB, Goddard J, James Jr AE: Basic concepts of ultrasound tissue characterization. Radio Clin North Am, 18: 21-30, 1980.

9. Ian R Wilson, Ernest F Crocker, Geoff McKellar: An evaluation of the clinical applications of diagnostic Ultrasonography in oral surgery. Oral Surg Oral Med Oral Pathol, 67 : 242-248, 1989.

10. Khanna JN, Andrade NN : Oral submucous fibrosis: A new concept in surgical management. Report of 100 cases. Int J Oral Maxillofacial Surg, 124: 433-439, 1995.

11. Uchida H, Kobayashi K, Nagao M: Measurement in vivo of masticatory mucosal thickness with $20 \mathrm{MHz} B$ mode ultrasonic diagnostic equipment. J Dent Res, 68 : 95-100, 1989. 
12. Anil Shah, Sunanda Raj: Surgical Management of Oral Submucosal Fibrosis with the "Opus-5" Diode Laser. Journal Oral Laser Applicaton, 5 : 37-43, 2005.

13. Eger J, Muller HP, Heinecke A : ultrasonic determination of gingival thickness: subject variations and influence of tooth type and clinical features. J Clin Periodontal, 23 : 839-845, 1996.

14. Anil S, Beena VT, Nair RG, Kumar TV: Evaluation of serum $\beta_{2}$-microglobulin in premalignant and malignant lesions of the oral cavity. Oral Surg Oral Med Oral Pathol Oral Radiol Endod, 79 : 750-752, 1995.

15. Pindborg JJ, Bhonsle RB, Murthi PR, Gupta PC, Daftary DK, Mehta FS : Incidence and early forms of oral submucous fibrosis. Oral surg Oral med Oral pathol, $50:$ 40-44, 1980.

16. Canniff JP, Harvey W, Harris M: Oral submucous fibrosis : its pathogenesis and management. Br Dent J, 21: 429-434, 1986.

17. Harvey W, Scutt A, Meghji S, Canniff JP : Stimulation of human buccal mucosa fibroblasts in vitro by betel-nut alkaloids. Arch Oral Biol, 31 : 45-49, 1986.

18. Murti PR, Bhonsle RB, Gupta PC, Daftary DK, Pindborg JJ, Mehta FS: Etiology of oral submucous fibrosis with special reference to the role of arecanut chewing. J Oral Pathol Med, 24 : 145-152, 1995.

19. Daftary DK, Murti PR, Bhonsle RB, Gupta PC, Mehta FS, Pindborg JJ : Oral precancerous lesions and conditions of tropical interest. Prabhu SR, Wilson DF, Daftary DK, Johnson NW, editors. In Oral Diseases in the Tropics. Chapter 36, Oxford University Press. Delhi : India ; 1993. p.417-422.

20. Sinor PN, Gupta PC, Murti PR, Bhonsle RB, Daftary DK, Mehta FS, Pindborg JJ : A case control study of oral submucous fibrosis with special reference to the etiologic role of areca nut. J Oral Pathol Med, 19: 94 $-98,1990$.

21. Phatak AG: Lymphocyte subpopulations B, T and Null-in oral submucous fibrosis. Indian J Otolaryngol, 31: 72-75, 1979.

22. Phatak AG: Serum proteins and immunoglobulins in oral submucous fibrosis. Indian J Otolaryngology, 30 : 1-4, 1978.

23. Pindborg JJ, Zachariah J : Frequency of oral submucous fibrosis among 100 South Indians with oral cancer. Bulletin of WHO, 32: 750-753, 1965.

24. Mathew B, Warrier PKR, Zachariah J, Ramachandran $\mathrm{P}$ : Oesophageal changes in oral submucous fibrosis. J pathol and Bacterol, 349-353, 1967.

25. Misra SP, Misra V, Dwivedi M, Gupta SC: Oesophageal Subepithelial fibrosis: an extension of oral submucosal fibrosis. Postgrad Med J, 74: 733-736, 1998.

26. Pindborg JJ, Chawla TN, Srivastava AN, Gupta D, Melhotra ML: Clinical aspects of oral submucous fibrosis. Acta Odont Scandinav, 22 : 679-691, 1964.

27. Naseem Shah, Ranikumar, Singh MK : Hematological and histological studies in oral submucous fibrosis. JIDA, 64 : 383-388, 1993.

28. Rao ABN : Idiopathic palatal fibrosis. Br J Surg, 2325, 1962.

29. Kiran Kumar K, Saraswathi TR, Ranganathan K, Devi U, Elizabeth J : Oral submucous fibrosis: a clinico-histopathological study in Chennai. Indian J Dent Res, 18: 106-111, 2007.

30. Rooban T, Saraswathi TR, Zainab FH, Devi U, Elizabeth J, Ranganathan K : A light microscopic study of fibrosis involving muscle in oral submucous fibrosis. Indian J Dent Res, 16 : 131-134, 2005.

31. Shah N, Sharma PP: Role of chewing and smoking habits in the etiology of OSMF : a case-control study. J oral Pathol Med, 28: 475-479, 1998.

32. Maher R, Lee AJ, Warnakulasuriya KAAS, Lewis JA, Johnson NW: Role of areca nut in the causation of oral submucous fibrosis: A case control study in Pakistan. J Oral Pathol MedM, 23 : 65-69, 1994.

33. Muller HP, Schaller N, Eager T, Heinecke A : Thickness of masticatory mucosa. J Clin Perio, 27 : 431-436, 2000.

34. Ralf K.W. Schulze, Dejan Curic, Bernd d Hoedt: Bmode versus $\mathrm{A}$-mode ultrasonographic measurements of mucosal thickness in vivo. Oral Surg Oral Med Oral Pathol Oral Radiol Endod, 93 : 110-117, 2002.

35. Muller HP, Schaller N, Eager T : Ultrasonic determination of thickness of masticatory mucosa. A methodologic study. Oral Surg Oral Med Oral Pathol Oral Radiol Endod, 88 : 248-253, 1999.

36. Chaturvedi VN, Sharma AK, Chakrabarti S : Salivary coagulopathy and humoral response in oral submucous fibrosis (OSMF). JIDA, 62: 51-59, 1991.

37. Chiang CP, Hsieh RP, Chen THH, Cheng YF, Liu BY, Wang A, Sun JT, Kuo MYP: High incidence of autoantibodies in Taiwanese patients with oral submucous fibrosis. J Oral Pathol Med, 31 : 402-409, 2002.

38. Van Wyk CW, Rabie G, Martell RW, Hammond MG : HLA-Antigens in oral submucous fibrosis. J Oral Pathol Med, 23 : 23-27, 1994.

39. Lemmer J, Shear M : Oral submucous fibrosis-A possible case in a person of Caucasian descent. Br Dent J, 82 : 646-654, 1967. 